\title{
Contribution to the Modeling of a Solar Adsorption Refrigerator under the Climatic Conditions of Burkina Faso
}

\author{
Guy Christian Tubreoumya, ${ }^{1,2,3}$, Alfa Oumar Dissa1, Eloi Salmwendé Tiendrebeogo1, \\ Xavier Chesneau' ${ }^{2}$, Aboubacar Compaoré1, Kayaba Haro' ${ }^{1}$, Charles Didace Konseibo3, \\ Belkacem Zeghmati ${ }^{2}$, Jean Koulidiati ${ }^{1}$
}

${ }^{1}$ Laboratoire de Physique et de Chimie de l’Environnement (L.P.C.E), Université Ouaga I, Ouagadougou, Burkina Faso

${ }^{2}$ LAboratoire de Mathématiqueset PhySique (LA.M.P.S), Université de Perpignan Via Domitia (UPVD), Perpignan, France ${ }^{3}$ Centre Ecologique Albert Schweitzer (CEAS), Ouagadougou, Burkina Faso

Email: guytubreoumya@yahoo.fr

How to cite this paper: Tubreoumya, G.C., Dissa, A.O., Tiendrebeogo, E.S., Chesneau, X., Compaoré, A., Haro, K., Konseibo, C.D., Zeghmati, B. and Koulidiati, J. (2017) Contribution to the Modeling of a Solar Adsorption Refrigerator under the Climatic Conditions of Burkina Faso. Energy and Power Engineering, 9, 119-135.

https://doi.org/10.4236/epe.2017.92010

Received: January 27, 2017

Accepted: February 24, 2017

Published: February 27, 2017

Copyright $\odot 2017$ by authors and Scientific Research Publishing Inc. This work is licensed under the Creative Commons Attribution International License (CC BY 4.0).

http://creativecommons.org/licenses/by/4.0/

\begin{abstract}
This work concerns a dynamic modeling and a numerical simulation of the operation of an adsorption solar refrigeration system using the zeolite-water couple. For this, a mathematical model representing the evolution of heat and mass transfer at each component of the solar adsorption refrigerator has been developed. We have adopted the Dubinin-Astakhov model for the adsorption kinetics of the zeolite/water pair. This model allows to describe the phenomenon of adsorption and to calculate the rate of adsorbate (water) in the zeolite (adsorbent) as a function of the temperature and the pressure. The equations governing the operation of the solar adsorption refrigerator, deduced from the thermal and mass balances established at the collector adsorber, condenser and evaporator components, were solved by an implicit finite difference scheme and Gauss Seidel's iterative method. We have validated the model established by applying it to the model of Allouhi et al. 2014. We analyzed the influence of the adsorbate/adsorbent couples, the solar flux, the ambient temperature on the adsorption and desorption process. The temperature profiles obtained representing the temperature evolution of the glass, the absorbent plate, the zeolite-water mixture, the condenser, the evaporator, as well as the pressure and the adsorbed mass allowed us to evaluate the performance of the solar adsorption refrigerator. SCOP is higher the higher the solar flux captured by the collector-adsorber.
\end{abstract}

\section{Keywords}

Solar Refrigeration, Simulation, Adsorption, Zeolite/Water, Burkina Faso 


\section{Introduction}

Cold production is mainly achieved by compression machines whose operation requires the use of refrigerants and excessive consumption of electrical energy. These refrigerants, CFCs (chlorofluorocarbons), HCFCs (hydrochlorofluorocarbons) and HFCs (hydrofluorocarbons) are harmful to the ozone layer and contribute to an increase in the greenhouse effect. Since the Montreal Protocol in 1987, international agreements have been signed to reduce emissions of these refrigerants [1]. Thus, research efforts focused on the development of refrigeration technologies, which respond to environmental and energy concerns, have been undertaken. Solar adsorption refrigeration machines have been the subject of numerous studies [2] [3] [4].

These machines are an alternative to solve both ecological and energy problems. Indeed, the technology of these machines is simple, maintenance is easy, and the materials used, are recyclable [5]. In addition, these machines use refrigerants such as water [6], methanol [7] and ammonia [8], which have no effect on the environment. For countries such as Burkina Faso, with favorable sunshine with an average irradiation between $5.5 \mathrm{kWh} \cdot \mathrm{m}^{-2} \cdot$ day $^{-1}$ and $65 \mathrm{kWh} \cdot \mathrm{hm}^{-2} \cdot \mathrm{day}^{-1}$ [9], solar adsorption refrigeration is a promising solution to meet important needs such as food preservation, pharmaceuticals, air conditioning, etc. and also to reduce electricity consumption.

However, some disadvantages have become obstacles to the actual application and marketing of these machines such as discontinuous cycle operation [10] [11], low coefficient of performance, poor heat and mass transfer in the bed Adsorbent [12], low thermal conductivity of the adsorbent [13] [14] [15], poor contact between the surface of the adsorber and the adsorbent [16] [17].

To improve the performance of solar adsorption refrigeration machines, numerous research axes have been proposed, studied and tested. Thus, several solar collector models have been used by researchers to optimize the solar radiation received through use: vacuum tube collectors [18] [19] [20] of the single-glazed or double-glazed (TIM) flat plate collectors [21] [22] [23], cylindro-parabolic collectors [24] [25].

Other approaches based on the shape of the adsorber have been used to improve the efficiency of solar radiation. Thus, flat, tubular adsorbers, equipped with external or internal fins, have been used in several prototypes of adsorption solar refrigerators. These fins act as thermal bridges between the absorbent plate and the reactive (porous) medium and thus optimize the heat and mass transfer in the adsorbent bed [12] [17] [26] [27] [28].

In addition, some researchers have focused on improving the thermal conductivity of adsorbents through the development of composite adsorbent. The technique for preparing the consolidated composite adsorbents consists in adding a material having a higher thermal conductivity to the powder of the conventional solid adsorbent. By this technique, thermal conductivity of the order of 5 to $15 \mathrm{~W} / \mathrm{m} \cdot \mathrm{k}$ can sometimes be reached and a heat exchange coefficient with the metal walls of the adsorber ranging from 200 to $3000 \mathrm{~W} / \mathrm{m}^{2} \cdot \mathrm{k}$ [26] [29] [30] 


\section{[31] [32] [33].}

In addition, to overcome the intermittent character of the solar adsorption refrigeration cycle, prototype models of machines have been developed. These machines consist of two beds of adsorbents operating so that one adsorbs the refrigerant and the other one desorbs it. Thus, they make it possible to produce cold continuously [7] [34] [35] [36].

The efficiency of the operation of the refrigerating machines is also linked to the climatic conditions of the site in which the machine is located. Thus, several experimental studies on prototypes of adsorption solar refrigerators have been proposed and tested, in order to find their actual behavior [23] [37] [38] [39] [40].

The main objective of this study is to contribute to the understanding of the solar refrigeration system by adsorption through a dynamic modeling of a solar adsorption refrigerator model operating under the climatic conditions of Burkina Faso.

\section{Materials and Methods}

\subsection{Description of the Cycle of Operation of the Solar Adsorption Refrigerator}

A solar refrigerating adsorption machine operates in a cycle. It consists in a flat plate collector containing the zeolite/water mixture and plays a role of capturing and releasing the heat. It is connected to a condenser and an evaporator. The principle of operation of these machines is based on the phenomena of adsorption-desorption of a gas (water vapor) in a solid (zeolite). This chemical reaction is exo or endothermic according to its direction of unwinding. This ideal cycle represents the evolution of the state of the adsorbent/adsorbate mixture contained in the collector-adsorber. Each cycle includes two main stages governing the operation: one stage for heating the zeolite/water mixture and another for cooling the same mixture.

\subsubsection{Heating Phase}

- Isosteric heating phase $(1 \rightarrow 2)$

At the beginning of the cycle (point 1), the zeolite/water mixture is at its minimum temperature $T_{a}$ (adsorption temperature) and at the pressure $P_{e v}$ (evaporation pressure); at this time, the collector-adsorber is isolated. Under heating, the pressure and temperature of the mixture increase, while the total mass of adsorbed water remains constant along the transformation $(1 \rightarrow 2)$ and equal to $q_{\max }$. This pressurization phase ends as soon as the pressure becomes equal to that prevailing in the condenser $P_{c d}$ (point 2). The temperature reached is called desorption threshold temperature $T_{s 1}$.

- Condensation desorption phase $(2 \rightarrow 3)$

This phase begins when the pressure of the mixture in the adsorber reaches the condensation pressure $P_{c d}$ (saturation pressure corresponding to the temperature of the condenser), the adsorber is placed in communication with the 
condenser and the desorption of the refrigerant begins, which condenses in the condenser thereafter. The adsorber is then in high pressure and follows the isobar imposed by the condenser. While continuing heating, the temperature of the mixture in the adsorber increases to the maximum temperature $T_{g}$ (regeneration temperature) at point 3 , set for the corresponding cycle. This phase is generally called generation because it is that which makes the adsorber conducive to a new phase of refrigeration production.

\subsubsection{Cooling Phase}

- Isosteric cooling phase $(3 \rightarrow 4)$

In contrast to the first phase, cooling of the zeolite/water mixture begins at point 3, where the temperature and pressure decrease until the pressure becomes equal to that in the evaporator. The temperature reached is referred to as the adsorption threshold temperature $T_{\mathrm{s} 2}$ (point 4). The total mass of the adsorbed fluid remains constant during this phase and is equal to $q_{\min }$.

- Adsorption-evaporation phase $(4 \rightarrow 1)$,

This phase is the motor phase of the cycle during which the cold is produced. At point 4 , the evaporation of the refrigerant begins, producing cold in the evaporator. The vapor produced is adsorbed again in the adsorber until the temperature of the zeolite water mixture becomes minimal $T_{a}$, set for the corresponding cycle. During the transformation $(4 \rightarrow 1)$, the system follows the isobara imposed by the evaporator and which corresponds to the saturation pressure of the refrigerant (water) at the evaporation temperature. At this point, the machine is ready for a new cycle.

Figure 1 shows the basic thermodynamic route of such a machine in the Clapeyron diagram (LnP; -1/T) (Figure 2).

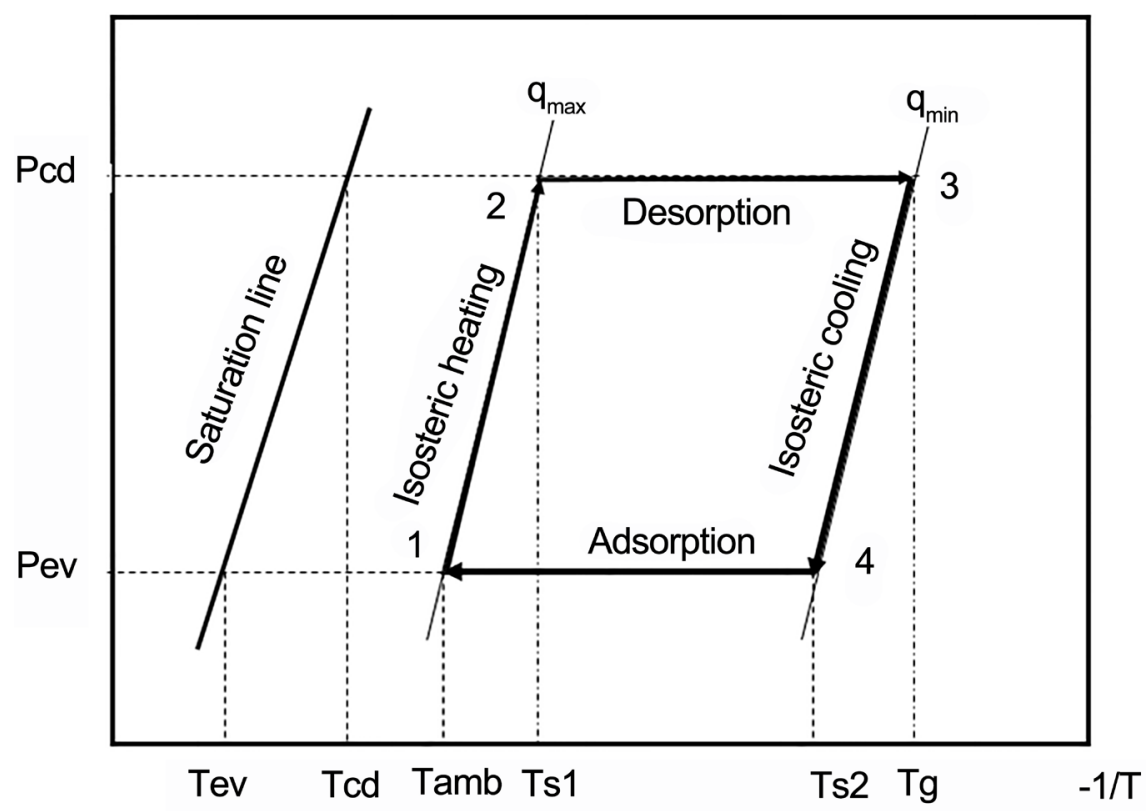

Figure 1. Theoretical cycle of an adsorption machine. 

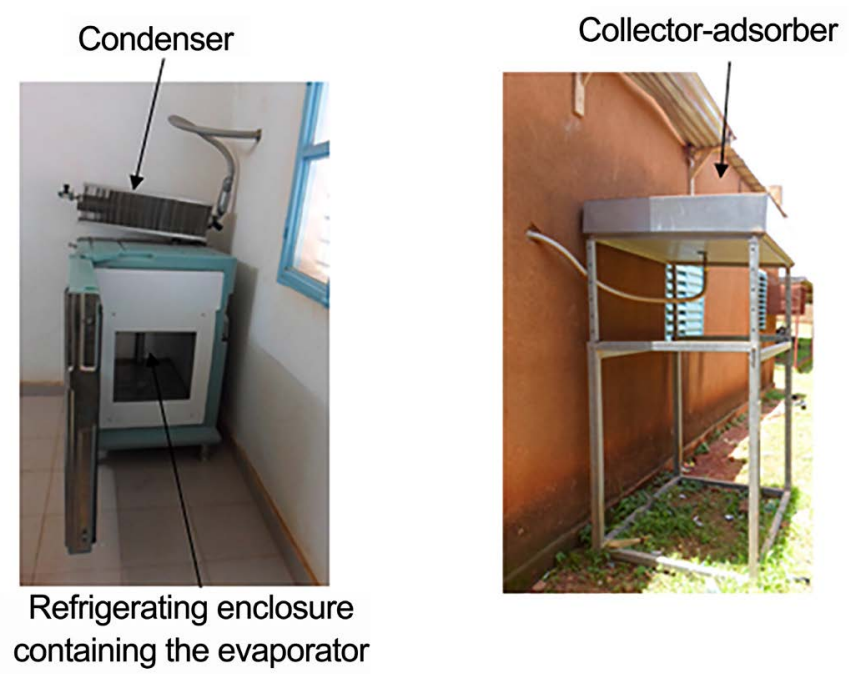

Figure 2. Photography of solar adsorption refrigerator.

\subsection{Modelisation}

The mathematical model presented below simulates the real operation of the solar adsorption refrigeration system taking into account the variation in solar radiation and the ambient temperature during the day. Thus, we present the modeling of the transfer of heat and mass in the adsorbent bed, and the balance equations at each compartment of the system (glass, absorbent plate, condenser, and evaporator).

\subsubsection{Assumptions}

The formulation of some assumptions is necessary for an approximate simulation of the system. Thus we assume that:

- The porous material (adsorbent) is assimilated to a medium having a temperature $\mathrm{T}$ and equivalent thermal conductivity,

- Heat transfer is unidirectional,

- The convective heat transfer and the pressure losses are neglected in the porous medium,

- The pressure remains constant in the condenser and in the evaporator.

\subsubsection{Equations Balances}

The heat transfer equations at each part of the refrigerator can be written as follows:

The glass

$$
\begin{aligned}
m_{v} C_{p v} \frac{d T_{v}}{d t} & =\alpha_{v} \cdot G_{n} \cdot s_{v}+U_{p-v} \cdot s_{v}\left[T_{p}-T_{v}\right]-h_{c v-v-e x t} \cdot s_{v}\left[T_{v}-T_{a m b}\right] \\
& -h_{r-v-\text { ciel }} \cdot s_{v}\left[T_{v}-T_{\text {ciel }}\right]
\end{aligned}
$$

The absorbent plat

$$
m_{p} C_{p_{p}} \frac{d T_{p}}{d t}=\alpha_{p} \lambda_{v} \cdot s_{p} \cdot G_{n}-U_{p-v} \cdot s_{v}\left(T_{p}-T_{v}\right)-U_{p-a d s} \cdot s_{p}\left(T_{p}-T_{\text {zeo }}\right)
$$

The adsorbent bed 
During the isosteric heating and desorption phase

$$
\begin{aligned}
m_{e q} c_{p e q} \frac{d T_{\text {zeo }}}{d t} & =U_{p-a d s} \cdot s_{p}\left(T_{p}-T_{\text {zeo }}\right) \\
& +\delta\left(\Delta H_{d e s} m_{a d s} \frac{d q^{d}}{d t}+m_{a d s} c_{p l}\left(T_{\text {zeo }}-T_{c d}\right) \frac{d q^{d}}{d t}\right)
\end{aligned}
$$

During the isosteric cooling phase and adsorption

$$
\begin{aligned}
m_{e q} c_{p e q} \frac{d T_{z e o}}{d t} & =U_{p-a d s} \cdot s_{p}\left(T_{p}-T_{\text {zeo }}\right) \\
& +\delta\left(\Delta H_{a d s} m_{a d s} \frac{d q^{a}}{d t}-m_{a d s} c_{p l}\left(T_{z e o}-T_{e v}\right) \frac{d q^{a}}{d t}\right)
\end{aligned}
$$

With:

$\delta=0$ : During isosteric heating and cooling;

$\delta=1$ : During desorption and adsorption;

The condenser

$$
\begin{aligned}
& {\left[m_{c d} \cdot c_{p c d}+M_{d}(t) \cdot c_{p l}\right] \frac{d T_{c d}}{d t}} \\
& =m_{a d s} \cdot \frac{d q^{d}}{d t}\left(L_{c d}\left(T_{c d}\right)+c_{p l}\left(T_{e a u}-T_{c d}\right)\right) \\
& \quad-h_{r-c d-c i e l} \cdot S_{c d}\left(T_{c d}-T_{c i e l}\right)-h_{c v-c d-a m b} \cdot S_{c d}\left(T_{c d}-T_{a m b}\right)
\end{aligned}
$$

The evaporator

$$
\begin{aligned}
& {\left[m_{e v} c_{p e v}+\left(M_{d}(t)-\Delta q \cdot m_{a d s}\right) c_{p l}\right] \frac{d T_{e v}}{d t}} \\
& =-m_{a d s} \frac{d q}{d t}\left[L_{e v}\left(T_{e v}\right)+c_{p l}\left(T_{e a u}-T_{e v}\right)\right]-h_{c v-e v-a i r} S_{e v}\left(T_{e v}-T_{a i r}\right)
\end{aligned}
$$

\subsubsection{Model of Adsorption Kinetics}

Several theories of adsorption have been proposed in the literature to describe the process of the adsorption and desorption phenomenon. The Dubinin-Astakhov equation is used successfully to describe the adsorption of gas vapor on the adsorbent. Thus, this equation is used to calculate the rate of adsorbate (water) in the zeolite (adsorbent) as a function of temperature and pressure.

$$
q=w_{0} \rho_{l}(T) \exp \left(-D\left(T \ln \frac{P_{s}(T)}{P}\right)^{n}\right)
$$

where $\rho_{l}(T)$ is the density of the adsorbate (water) and $P_{s}(T)$ is the saturation pressure. $w_{0}$ is the maximum adsorption capacity; $\mathrm{D}$ and $\mathrm{n}$ are constants pedending on the adsorbent/adsorbate couple used.

\subsubsection{System Performance}

The solar performance coefficient (SCOP) of a solar refrigerating machine is defined as the ratio between the amount of cold produced at the evaporator and the total solar energy incident for a full day.

$$
S C O P=\frac{Q_{f}}{\int_{t_{s r}}^{t_{s s}} A_{s} \cdot G_{n} \cdot d t}
$$


where As is the collecting surface and $\mathrm{Gn}$ is the solar flux in $\mathrm{W} / \mathrm{m}^{2} \quad Q_{f}$ is the amount of cold produced at the evaporator, given by:

$$
Q_{f}=m_{a d s} \Delta m\left[L\left(T_{e v}\right)-\int_{T_{e v}}^{T_{c d}} C p_{l}(T) d T\right]
$$

\subsection{Numerical Methodology}

\subsubsection{Initial and Boundary Conditions}

For all $t \prec t_{0}, t_{0}$ being the instant from which the collector-adsorber is subjected to the solar flux, we have:

$$
\begin{gathered}
T_{v}\left(t_{0}\right)=T_{p}\left(t_{0}\right)=T_{e v}\left(t_{0}\right)=T_{c d}\left(t_{0}\right)=T\left(t_{0}\right)=T_{a m b} \\
P\left(t_{0}\right)=P_{e v}=P_{s}\left(T_{e v}\right) \\
q=q\left(T_{a m b}, P_{e v}\right)
\end{gathered}
$$

\subsubsection{Method of Resolution}

The method of solving the system of equations which describes the transient behavior of the model is purely numerical and based on the implicit finite difference method and the Gauss Seidel iterative method. We have developed and written in Fortran a computer program to model and simulate the adsorptiondesorption kinetics of the zeolite/water pair and on the other hand the operation of each element of the refrigerator during a day.

\section{Results and Discussion}

\subsection{Validation of the Model}

In order to validate our numerical code, we applied our code to the solar adsorption refrigerator model presented by A. Allouhi et al. [41]. This model describes a parallelepiped-shaped collector-adsorber refrigerator using the silicagel-water couple. A comparison between the changes in the temperature in the adsorbent bed as a function of its pressure, describing the Clapeyron cycle of the solar adsorption refrigerator, shows good quantitative agreement. Indeed, the maximum deviation observed for the temperatures is of the order of $1.1 \%$ and $2.4 \%$ for the pressure (Figure 3).

\subsection{Climatic Data}

Solar radiation and ambient temperature are parameters that affect the performance of solar refrigeration systems. Thus, using the weather data provided by the General Direction of Meteorology in Burkina Faso (DGM), which include the values of the monthly global radiation densities on a horizontal plane in $\mathrm{J} / \mathrm{cm}^{2}$, we used the method of Liu and Jordan to transform these data in order to obtain the hourly values of the global radiation on an inclined plane of angle $12.2^{\circ}$ with respect to the horizontal. For ambient temperature, we used the data of E. Ouédraogo et al. [42], who carried out a statistical study to develop an hourly weather file for the city of Ouagadougou. Thus, Figure 4(a) and Figure 4(b) 


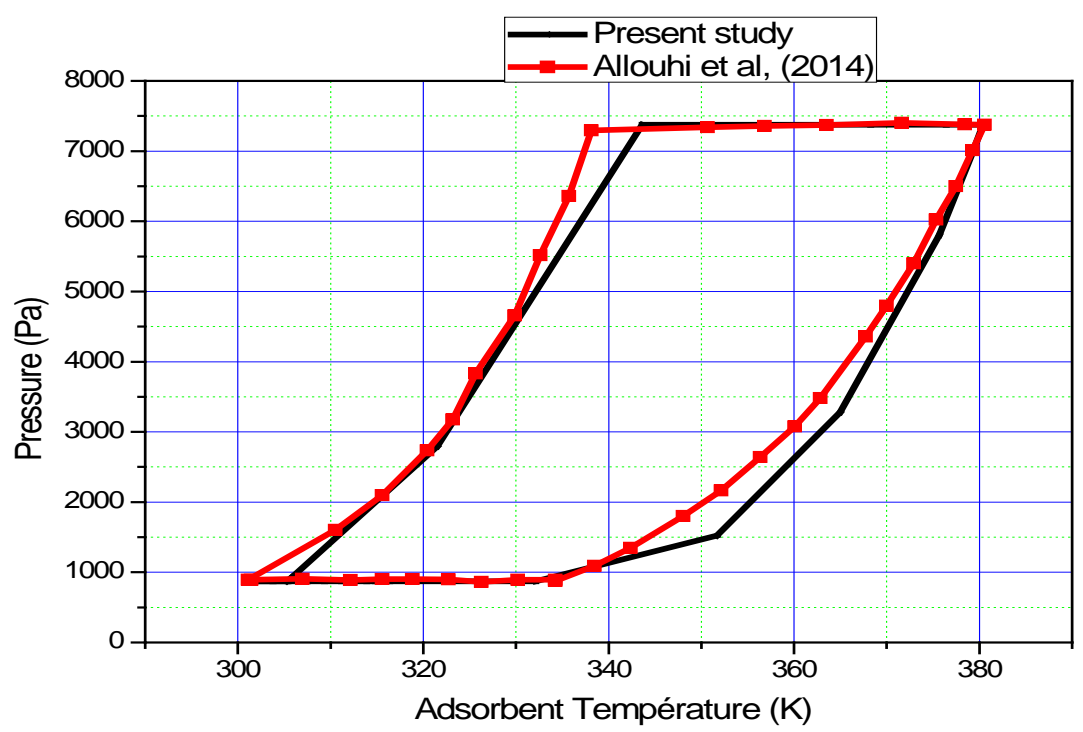

Figure 3. Comparison of the Clapeyron cycle given by A. Allouhi and our calculation code.

Table 1. Main parameters used in the simulation.

\begin{tabular}{|c|c|c|c|}
\hline Symbols & Paramters & Values & Units \\
\hline \multicolumn{4}{|c|}{ Properties of the adsorbent/adsorbate (zeolite/water) } \\
\hline $\mathrm{Cp}_{\mathrm{ads}}$ & Chaleur spécifique & 0.836 & {$\left[\mathrm{~kJ} \cdot \mathrm{kg}^{-1} \cdot \mathrm{K}^{-1}\right]$} \\
\hline $\mathrm{m}_{\mathrm{ads}}$ & Masse & 32 & {$[\mathrm{~kg}]$} \\
\hline$\rho_{\text {ads }}$ & Densité & 620 & {$\left[\mathrm{~kg} \cdot \mathrm{m}^{-2}\right]$} \\
\hline $\mathrm{Cp}_{1}$ & Chaleur spécifique & 4.18 & {$\left[\mathrm{~kJ} \cdot \mathrm{kg}^{-1} \cdot \mathrm{K}^{-1}\right]$} \\
\hline \multicolumn{4}{|c|}{ Collector-adsorber } \\
\hline$\varepsilon_{\mathrm{v}}$ & Emissivity of the glass & 0.9 & {$[-]$} \\
\hline$\tau_{\mathrm{v}}$ & Transmitivity of the glass & 0.95 & {$[-]$} \\
\hline$\alpha_{\mathrm{v}}$ & Absorptivity of the glass & 0.05 & {$[-]$} \\
\hline $\mathrm{e}_{\mathrm{v}}$ & Thickness of the glass & 0.04 & {$[\mathrm{~m}]$} \\
\hline S & Area & 1 & {$\left[\mathrm{~m}^{2}\right]$} \\
\hline $\mathrm{Cp} \mathrm{p}_{\mathrm{v}}$ & Specific heat of the glass & 0.75 & {$\left[\mathrm{~kJ} \cdot \mathrm{kg}^{-1} \cdot \mathrm{K}^{-1}\right]$} \\
\hline$C \mathrm{p}_{\mathrm{p}}$ & Specific heat of the absorbent plate & 0.896 & {$\left[\mathrm{~kJ} \cdot \mathrm{kg}^{-1} \cdot \mathrm{K}^{-1}\right]$} \\
\hline$e_{p}$ & Thickness of absorbent plate & 0.05 & {$[\mathrm{~m}]$} \\
\hline$\alpha_{\mathrm{p}}$ & Absorptivity of absorbent plate & 0.95 & {$[-]$} \\
\hline$\varepsilon_{\mathrm{p}}$ & Emissivity of the absorbent plate & 0.9 & {$[-]$} \\
\hline \multicolumn{4}{|c|}{ Parameters of Dubinin-Astakhov } \\
\hline $\mathrm{D}$ & $\begin{array}{l}\text { Characteristic parameter of the } \\
\text { adsorbent/adsorbate couple }\end{array}$ & $4.1510^{-7}$ & {$[-]$} \\
\hline $\mathrm{n}$ & $\begin{array}{l}\text { Characteristic parameter of the } \\
\text { adsorbent/adsorbate couple }\end{array}$ & 2 & {$[-]$} \\
\hline $\mathrm{W}_{\mathrm{o}}$ & Maximum adsorption capacity & $0.26910^{-3}$ & {$\left[\mathrm{~m}^{3} \cdot \mathrm{kg}^{-1}\right]$} \\
\hline
\end{tabular}




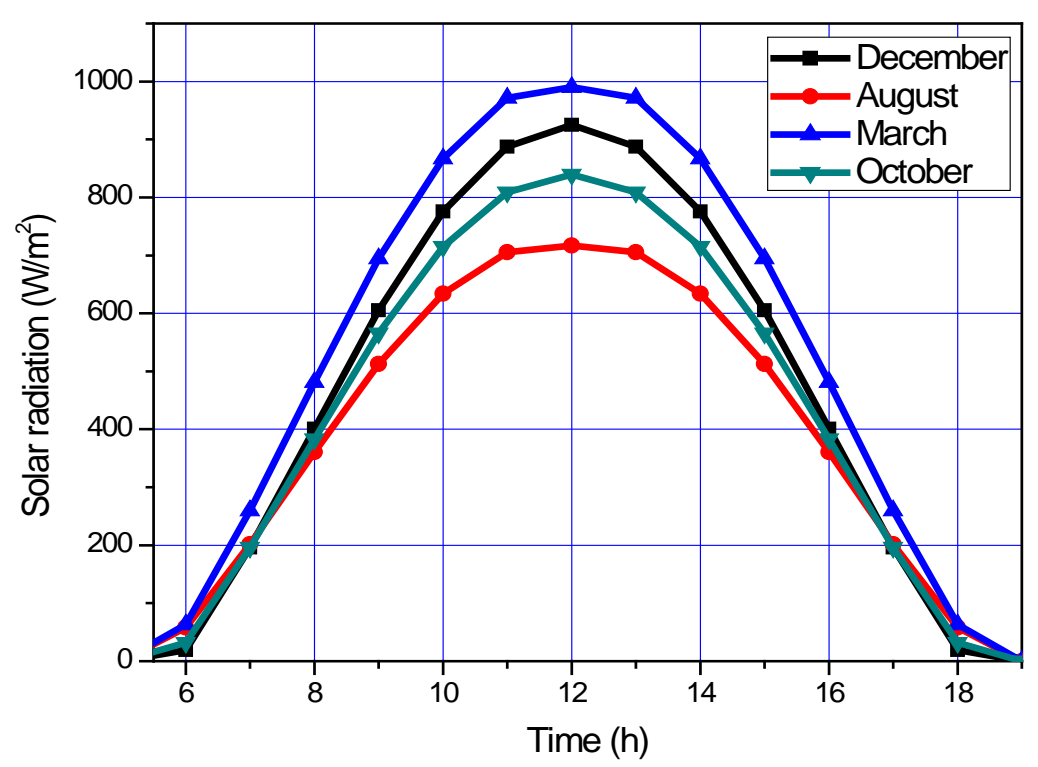

(a)

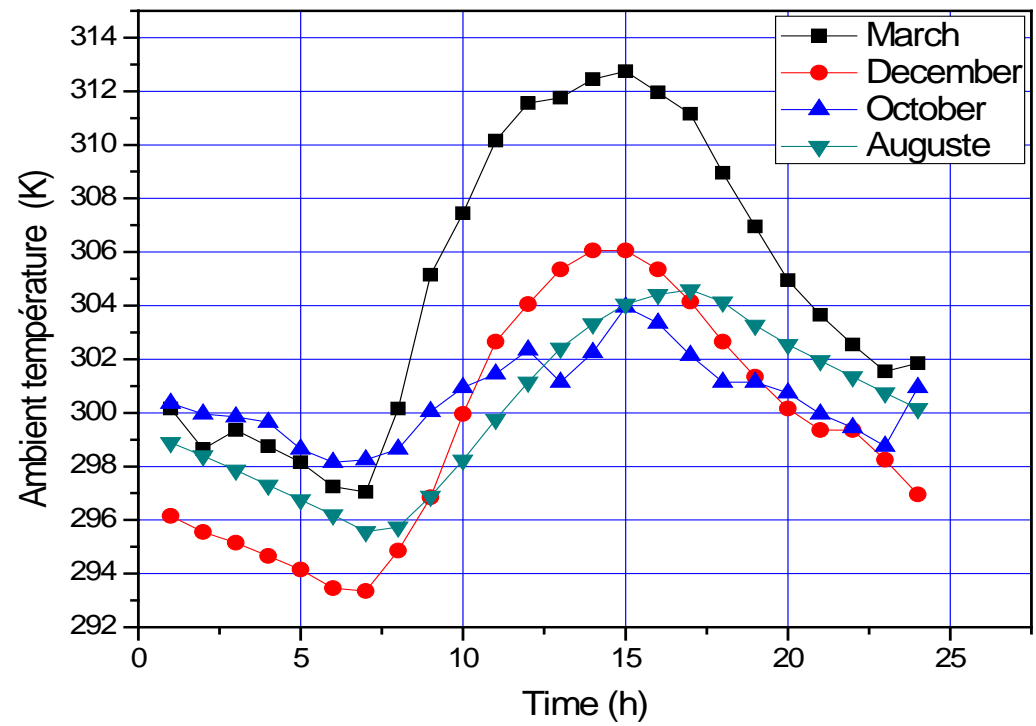

(b)

Figure 4. Hourly evolution of solar radiation and ambient temperature.

shows the hourly evolution of global solar radiation and the ambient temperature for December, August, October and March. It can be seen that the radiation is maximum in March and minimal in August, this can be explained by the clear sky in March and by a sky low in October and December. In August, this is due to the presence of dust and clouds. These values thus obtained and the values in Table 1 were used for the simulation of our model.

\subsection{Dynamic Behavior of the Solar Refrigerator}

Figure 5 shows the evolution of the temperature of the glass, the absorbent plate and the adsorbent bed (zeolithe) as a function of time during the four phases of 


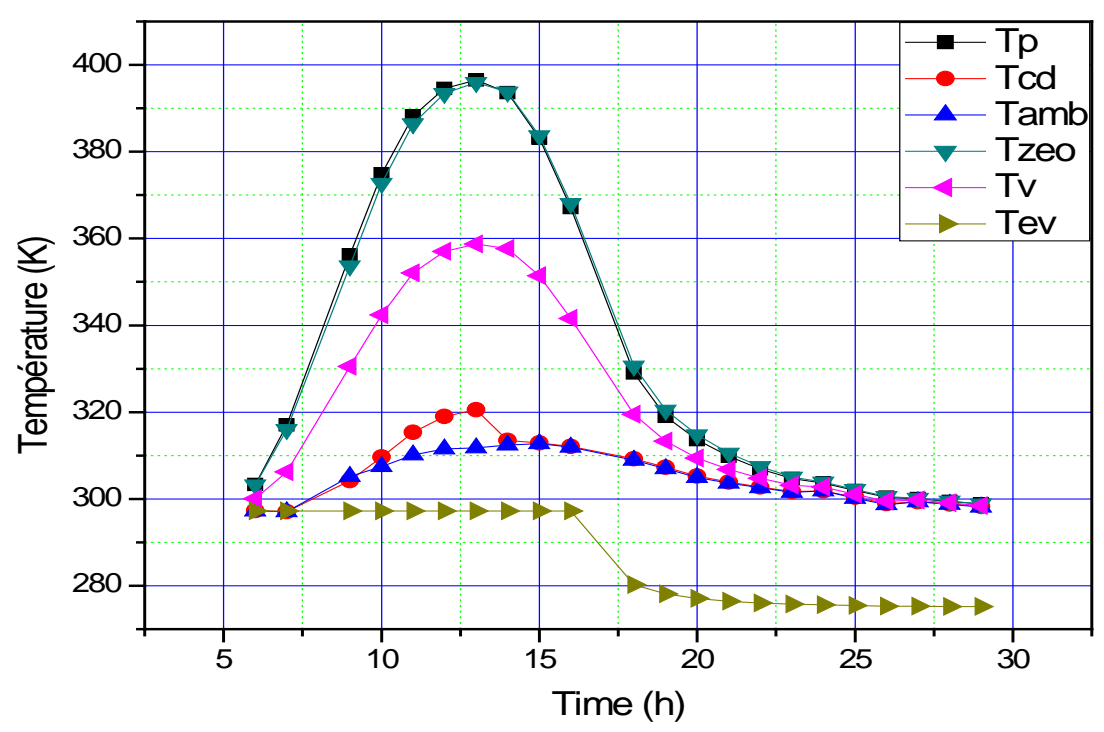

Figure 5. Time evolution of the temperature of the various components of the solar refrigerator for the month of March.

the cycle. At the beginning of the cycle (the initial state), the temperatures are uniform and equal to the adsorption temperature, which in turn equals the ambient temperature at sunrise. When the solar flux increases, the collector-adsorber heats up and the temperatures of its various components increase rapidly with time. They each reach a maximum $(\mathrm{Tv}=358 \mathrm{~K}, \mathrm{Tp}=396 \mathrm{~K}$, Tzeo $=395 \mathrm{~K})$ at about 13 o'clock. The maximum temperature of the adsorbent bed is referred to as the regeneration temperature, that is to say the temperature at which there is no heat exchange between the plate and the adsorbent bed. When the solar flux decreases, the collector-adsorber cooling begins. The temperatures of the various compartments decrease until the temperature reaches $300 \mathrm{~K}$. This temperature represents the temperature in which there is no exchange between the glass pane, the plate and the adsorbent bed.

The evolution of the temperature of the condenser during the cycle is also shown in Figure 5. At the beginning of the cycle, the temperature of the condenser is the same as that of the ambient. This is explained by the fact that the condenser is isolated from the collector-adsorber during this period. When the desorption-condensation phase begins, the self-contained valve opens and the desorbed water vapor flows into the condenser, resulting in an increase in its temperature. At about 14 o'clock, the temperature of the condenser reaches its maximum at $\mathrm{Tcd}=320 \mathrm{~K}$, after which it begins to decrease. This increase in condenser temperature is due in large part to the latent heat of condensation of the water. The decrease of the temperature after 14 o'clock is due, on the one hand, to the cessation of the desorption process and, on the other hand, to cooling by means of the convection and the radiation which the condenser exchanges with the ambient medium. The temperature of the condenser begins to follow that of the ambient temperature during the rest of the day. 
The evolution of the temperature of the evaporator is also shown in the same Figure 5. The temperature of the evaporator decreases from $297 \mathrm{~K}$ to $275 \mathrm{~K}$. This cooling of the evaporator is due to the evaporation of the condensate (water) from the evaporator to the adsorbent bed. Thus, the adsorbate withdraws the needed heat for phase change of the refrigerating enclosure where the evaporator is located. This results in cooling.

Figure 6 shows the variation of the pressure within the adsorbent bed as a function of time. During the phases of the operating cycle, the pressure has a logical behavior with the evolution of the temperature. It increases rapidly from the evaporation pressure $\mathrm{Pev}=872 \mathrm{~Pa}$ (equal to the saturation pressure at the evaporation temperature) up to a maximum value corresponding to the condensation pressure $\mathrm{Pcd}=7376 \mathrm{~Pa}$ (equal to the saturation pressure at the condensation temperature). During the desorption phase, the pressure remains constant and equal to the condensation pressure until the temperature of the adsorbent bed reaches the maximum regeneration temperature. Then, it begins to decrease to the low initial evaporation pressure.

The distribution of the quantity of water adsorbed during the four phases of the cycle is also shown in the same figure. During the cycle, the total quantity of water adsorbed in the adsorbent bed decreases during the desorption phase and then increases during adsorption. It remains constant during the isosteric heating and cooling phases.

\subsection{Comparison of the Results of the 4 Months}

The evolution of the temperature, the pressure and the quantity of water adsorbed in the adsorbent bed are respectively represented in Figures 7-9. It is clear that the climatic data have a great influence on the Performance of the solar refrigerator. Indeed, for the month of March, the values of the temperature,

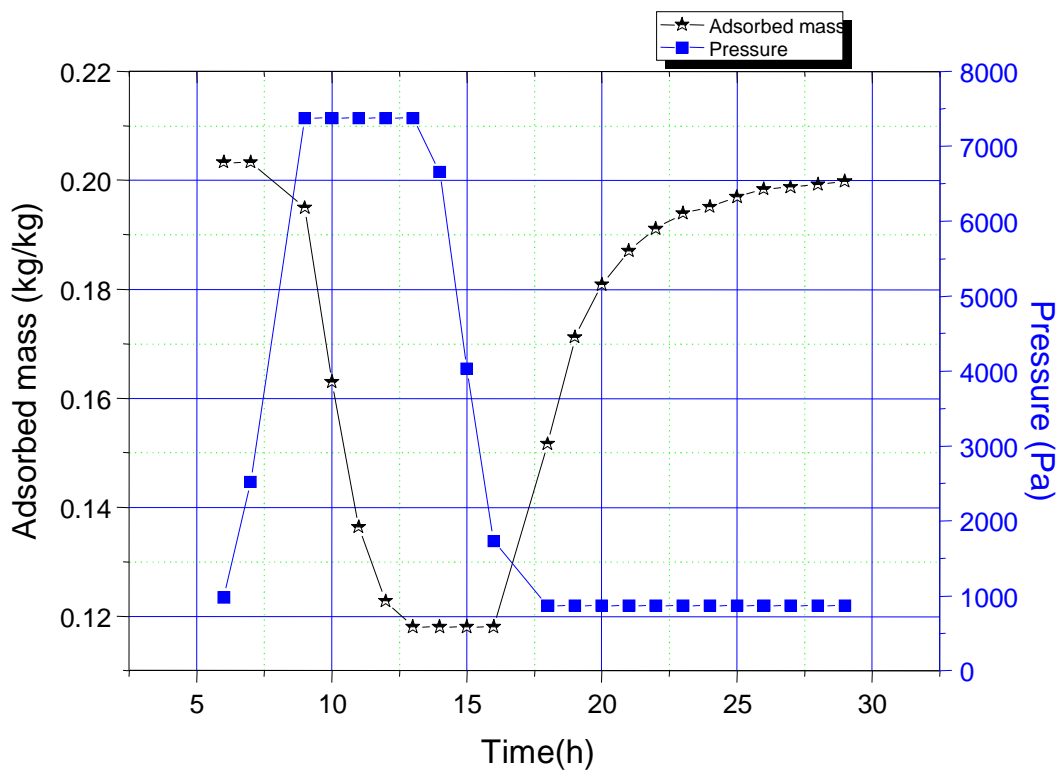

Figure 6. Evolution of the pressure and the adsorbed mass for the month of March. 


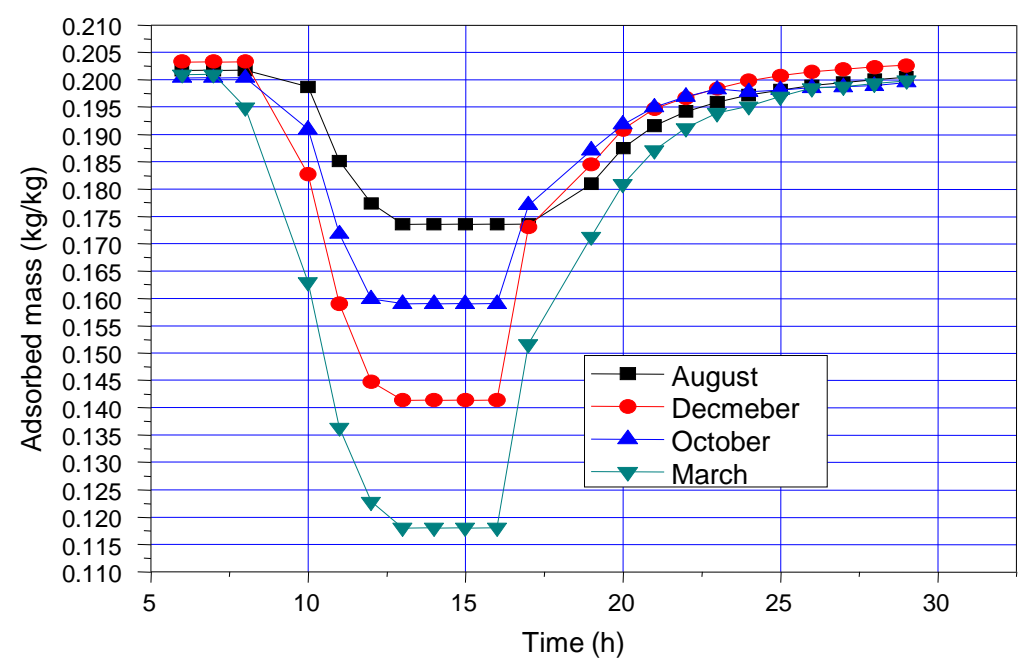

Figure 7. Comparison of the evolution of the adsorbed mass during the 4 months.

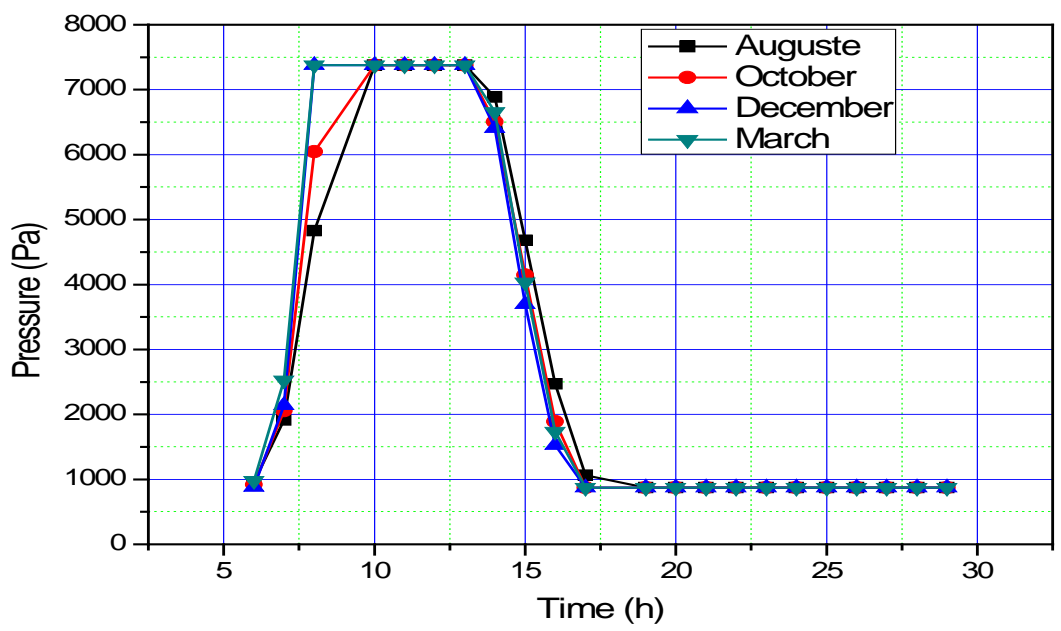

Figure 8. Comparison of the evolution of the pressure during the 4 months.

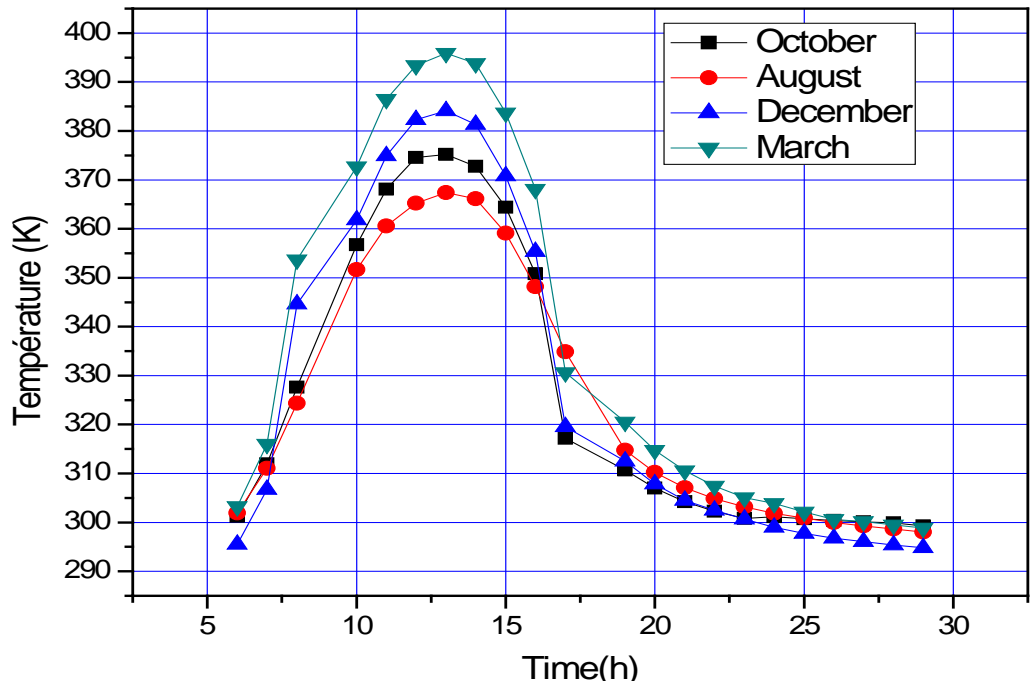

Figure 9. Comparison of the evolution of the temperature of the zeolite during the 4 months. 
Table 2. Coefficient of performance of the solar adsorption refrigerator.

\begin{tabular}{ccccc}
\hline Month & August & October & December & March \\
\hline Qf $[\mathrm{MJ}]$ & 2,1098 & 3,0965 & 4,642 & 6,391 \\
Gn-moy $\left(\mathrm{W} / \mathrm{m}^{2}\right)$ & 435,597 & 479,980 & 514,916 & 589,636 \\
SCOP & 0,113 & 0,151 & 0,211 & 0,253 \\
\hline
\end{tabular}

of the quantity of desorbed adsorbate, are higher compared to the other three months. This is due to the fact that the solar flux density is maximum during this month $\left(990 \mathrm{~W} / \mathrm{m}^{2}\right)$. The performances of the solar adsorption refrigerator for the four months are also shown in the Table 2. For the month of March, the SCOP reached is 0.25 , while for the other months the SCOP is equal to 0.21 for the month of December, 0.15 for the month of October and 0.11 for the month of August.

\section{Conclusions}

This work presents the modeling of a system of solar refrigeration by adsorption which uses the couple zeolite and water. Thus, through a mathematical model, we wrote the equations of balance at each part of the refrigerator and developed a program written in Fortran language in order to simulate the behavior of the refrigerator taking into account the climatic conditions of the city of Ouagadougou. The temperature changes of the glass, the absorbent plate, the condenser, the evaporator, the adsorbent bed and its pressure and the adsorbed mass were discussed.

The key findings are:

- For March and December, the average solar flux densities are $590 \mathrm{~W} / \mathrm{m}^{2}$ and $514 \mathrm{~W} / \mathrm{m}^{2}$ respectively. The amount of cold produced during these months is 6.391 MJ for the month of March and 4.642 MJ for the month of December. This gives a SCOP of 0.25 and 0.21 for the months of March and December.

- With an average daily solar flux density of $436 \mathrm{~W} / \mathrm{m}^{2}$ and $480 \mathrm{~W} / \mathrm{m}^{2}$ respectively for the months of August and October, the SCOP reached by our solar refrigeration system is 0.11 and 0.15 , with a total product amount of 2.12 and 3.1 MJ.

The dynamic model thus developed allows to predict the real operation of the solar adsorption refrigerator and to evaluate its performance according to the climatic conditions of the city of Ouagadougou (Burkina Faso) for the hottest months and the coldest months of the year. The results obtained are very encouraging to continue to improve the performance of the solar adsorption refrigerator in order to use it in industrial and domestic domains.

\section{Acknowledgements}

The authors are grateful to the University Agency of the Francophonie (AUF) and the French Embassy (SCAC) for financial support which allowed the realization of this work. 


\section{References}

[1] Anyanwu, E. (2000) Environmental Pollution: Restructuring the Refrigeration Industry as a Way out. Environment Protection Engineering, 26, 17-28.

[2] Hadj Ammara, M., Benhaoua, B. and Balghouthi, M. (2015) Simulation of Tubular Adsorber for Adsorption Refrigeration System Powered by Solar Energy in SubSahara Region of Algeria. Energy Conversion and Management, 106, 31-40. https://doi.org/10.1016/j.enconman.2015.09.013

[3] Umair, M., Akisawa, A. and Ueda, Y. (2014) Performance Evaluation of a Solar Adsorption Refrigeration System with a Wing Type Compound Parabolic Concentrator. Energies, 7, 1448-1466. https://doi.org/10.3390/en7031448

[4] Qasem, N. and El-Shaarawi, M. (2013) Improving Ice Productivity and Performance for an Activated Carbon/Methanol Solar Adsorption Ice-Maker. Solar Energy, 98, 523-542. https://doi.org/10.1016/j.solener.2013.10.018

[5] Chikouche, A. (2012) Using Solar Energy for Refrigeration Purposes in Algeria.

[6] Uyun, M.A., Miyazaki, T., Ueda, Y. and Akisawa, A. (2010) Performance Analysis of a Double-Effect Adsorption Refrigeration Cycle with a Silica Gel/Water Working Pair. Energies, 3, 1704-1720. https://doi.org/10.3390/en3111704

[7] Hassan, H., Mohamad, A. and Al-Ansary, H. (2012) Development of a Continuously Operating Solar-Driven Adsorption Cooling System: Thermodynamic Analysis and Parametric Study. Applied Thermal Engineering, 48, 332-341.

https://doi.org/10.1016/j.applthermaleng.2012.04.040

[8] Louajari, M., Mimet, A. and Ouammi, A. (2011) Study of the Effect of Finned Tube Adsorber on Theperformance of Solar Driven Adsorption Cooling Machine Using Activated Carbon-Ammonia Pair. Applied Energy, 88, 690-698. https://doi.org/10.1016/j.apenergy.2010.08.032

[9] Ousmane, M., Dianda, B., Kam, S., Konfe, A., Ky, T. and Bathiebo, D. (2015) Experimental Study in Natural Convection. Global Journal of Pure and Applied Sciences, 21, 155-169. https://doi.org/10.4314/gjpas.v21i2.8

[10] Anyanwu, E. (2003) Review of Solid Adsorption Solar Refrigerator I: An Overview of the Refrigeration Cycle. Energy Conversion and Management, 44, 301-312. https://doi.org/10.1016/S0196-8904(02)00038-9

[11] Meunier, F. (2001) Adsorptive Cooling: A Clean Technology. Clean Products and Processes, 3, 8-20. https://doi.org/10.1007/s100980000096

[12] Fadar, A.E. (2015) Thermal Behavior and Performance Assessment of a Solar Adsorption Cooling System with Finned Absorber. Energy, 83, 674-684. https://doi.org/10.1016/j.energy.2015.02.074

[13] Critoph, R.E. (1999) Adsorption Refrigerators and Heat Pumps. In: Burchell, T.D., Ed., Carbon Materials for Advanced Technologies, Elsevier, Amsterdam, 303-340. https://doi.org/10.1016/B978-008042683-9/50012-1

[14] Mhimid, A., Jemni, A.A. and Nasrallah, B.S. (1997) Etude théorique des transferts couples de chaleur et de masse lors de la désorption du couple Zéolithe 13X-eau. Revue Générale de Thermique, 36, 697-706. https://doi.org/10.1016/S0035-3159(97)88434-6

[15] Jemni, A. and Ben Nasrallah, S. (1995) Study of Two-Dimensional Heat and Mass Transfer during Desorption in a Metal-Hydrogen Reactor. International Journal of Hydrogen Energy, 20, 881-891. https://doi.org/10.1016/0360-3199(94)00115-G

[16] Critoph, R. and Turner, L. (1995) Heat Transfer in Granular Activated Carbon Beds in the Presence of Adsorbable Gases. International Journal of Heat and Mass Transfer, 38, 1577-1585. https://doi.org/10.1016/0017-9310(94)00276-2 
[17] Almers, A., Azzabakh, A. and Mimet, A. (2006) Optimal Design Study of Cylindrical Finned Reactor for Solar Adsorption Cooling Machine Working with Activated Carbon-Ammonia Pair. Applied Thermal Engineering, 26, 1866-1875. https://doi.org/10.1016/j.applthermaleng.2006.01.021

[18] Chekirou, W., Boukheit, W. and Kerbache, T. (2007) Numerical Modeling of Combined Heat and Mass Transfer in a Tubular Adsorber of a Solid Adsorption Solar Refrigerator. Revue des Energies Renouvelables, 10, 367-379.

[19] Hassan, H., Mohamad, A. and Bennacer, R. (2011) Simulation of an Adsorption Solar Cooling System. Energy, 36, 530-537. https://doi.org/10.1016/j.energy.2010.10.011

[20] Mohamed, L., Abdelaziz, M. and Ahmed, O. (2011) Study of the Effect of Finned Tube Adsorber on the Performance of Solar Driven Adsorption Cooling Machine Using Activated Carbon-Ammonia Pair. Applied Energy, 88, 690-698. https://doi.org/10.1016/j.apenergy.2010.08.032

[21] Naef, A., Qasem, M. and El-Shaarawi, A. (2013) Improving Ice Productivity and Performance for an Activated Carbon/Methanol Solar Adsorption Ice-Maker. Solar Energy, 98, 523-542. https://doi.org/10.1016/j.solener.2013.10.018

[22] Li, M., Sun, C., Wang, R. and Cai, W. (2004) Development of No Valve Solar Ice Maker. Applied Thermal Engineering, 24, 865-872.

https://doi.org/10.1016/j.applthermaleng.2003.10.002

[23] Leite, A., Grilo, M., Andrade, R., Belo, F. and Meunier, F. (2007) Experimental Thermodynamic Cycles and Performance Analysis of a Solar-Powered Adsorptive Ice Maker in Hot Humid Climate. Energy Renewable, 32, 697-712. https://doi.org/10.1016/j.renene.2006.03.002

[24] Muhammad, U., Atsushi, A. and Yuki, U. (2014) Performance Evaluation of a Solar Adsorption Refrigeration System with a Wing Type Compound Parabolic Concentrator. Energies, 7, 1448-1466. https://doi.org/10.3390/en7031448

[25] Bakkas, M., Mada, M. and Tahri, M. (2001) Modélisation et Simulation du Transfert de Chaleur et de Masse à l'Intérieur d'un Réacteur de Charbon Actif Réagissant avec de l'Ammoniac Couplé à un Caloduc Annulaire à Eau. Revue des Energies Renouvelables, 19-24.

[26] Allouhi, A., Kousksou, T., Jamil, A., El Rhafiki, T., Mourad, Y. and Zeraouli, Y. (2015) Optimal Working Pairs for Solar Adsorption Cooling Applications. Energy, 79, 235-247. https://doi.org/10.1016/j.energy.2014.11.010

[27] Leite, A.D.M. (2000) Performance of a New Solid Adsorption Ice Maker with Solar Energy Regeneration. Energy Conversion and Management, 41, 1625-1647. https://doi.org/10.1016/S0196-8904(00)00011-X

[28] Guilleminot, J.M.F. (1987) Heat and Mass Transfer in a Non Isothermal Fixed Bed Solid Adsorbent Reactor a Uniform Pressure-Non Uniform Temperature. International Journal of Heat and Mass Transfer, 30, 1595-1606. https://doi.org/10.1016/0017-9310(87)90304-8

[29] Mimet, A. (1991) Etude théorique et expérimentale d'une machine frigorifique à adsorption d'ammoniac sur charbon actif. Thèse de Doctorat, FPMs, Mons.

[30] Iloeje, O., Ndili, A. and Enibe, S. (1995) Computer Simulation of a $\mathrm{CaCl}_{2}$, Solid Adsorption Solar Refrigerator. Energy, 20, 1141-1151.

https://doi.org/10.1016/0360-5442(95)00050-Q

[31] Eun, T.-H., et al. (2000) Enhancement of Heat and Mass Transfer in Silica-Expanded Graphite Coposite Blocks for Adsorption Heat Pumps: Part I. Characterisation of the Composite Blocks. International Journal of Refrigeration, 23, 64-73. https://doi.org/10.1016/S0140-7007(99)00035-3 
[32] Lemmini, F. and Errougani, A. (2007) Experimentation of a Solar Adsorption Refrigerator in Morocco. Renewable Energy, 32, 2629-2641. https://doi.org/10.1016/j.renene.2007.01.004

[33] Pons, M., Laurent, D. and Meunier, F. (1996) Experimental Temperature Fronts For Adsorptive Heat Pump Applications. Applied Thermal Engineering, 16, 395-404. https://doi.org/10.1016/1359-4311(95)00025-9

[34] Rahman, A., Miyazaki, T., Ueda, Y., Saha, B. and Akisawa, A. (2013) Performance Comparison of Three-Bed Adsorption Cooling System with Optimal Cycle Time Setting. Heat Transfer Engineering, 34, 938-947. https://doi.org/10.1080/01457632.2012.753571

[35] Uyun, A., Akisawa, A., Miyazaki, T., Ueda, Y. and Kashiwagi, T. (2009) Numerical Analysis of an Advanced Three-Bed Mass Recovery Adsorption Refrigeration Cycle. Applied Thermal Engineering, 29, 2876-2884. https://doi.org/10.1016/j.applthermaleng.2009.02.008

[36] Muhammad, U., Atsushi, A. and Yuki, U. (2014) Simulation Study of Continuous Solar Adsorption Refrigeration System Driven by Compound Parabolic Concentrator. Renewable Energy Journal, 7, 1-12. https://doi.org/10.2174/1876387101407010001

[37] Lemmini, F., Buret-Bahraoui, J., Pons, M. and Meunier, F. (1992) Simulation des performances d'un réfrigérateur solaire à adsorption: 1. Comparaison des performances pour deux types de charbon actif. International Journal of Refrigeration, 15, 159-167. https://doi.org/10.1016/0140-7007(92)90006-G

[38] Boubakri, A., Guilleminot, J. and Meunier, F. (2000) Adsorptive Solar Powered Ice Maker: Experiments and Model. Solar Energy, 69, 249-263. https://doi.org/10.1016/S0038-092X(00)00063-3

[39] Kreussler, S. and Bolz, D. (2000) Experiments on Solar Adsorption Refrigeration Using Zeolite and Water. Laboratory for Solar Energy, University of Applied Sciences, Lubeck.

[40] Li, M., Wang, R., Xu, Y., Wu, J. and Dieng, A. (2002) Experimental Study on Dynamic Performance Analysis of a Flat-Plate Solar Solid-Adsorption Refrigeration for Ice Maker. Renewable Energy, 27, 211-221. https://doi.org/10.1016/S0960-1481(01)00188-4

[41] Allouhi, A., Kousksou, T., Jamil, A. and Zeraouli, Y. (2014) Modeling of a Thermal Adsorber Powered by Solar Energy for Refrigeration Applications. Energy, 75, 589-596. https://doi.org/10.1016/j.energy.2014.08.022

[42] Ouedraogo, E., Coulibaly, O. and Ouedraogo, A. (2012) Elaboration d'une année météorologique type de la ville de Ouagadougou pour l'étude des performances énergétiques des bâtiments. Revue des Energies Renouvelables, 15, 77-90. 


\section{Nomenclature}

\begin{tabular}{|c|c|c|c|}
\hline $\mathrm{Cp}$ & Spécific heat (J/kg.K) & $\Delta H$ & $\begin{array}{c}\text { Heat of } \\
\text { adsorption/desorption }(\mathrm{J} / \mathrm{kg})\end{array}$ \\
\hline $\mathrm{D}$ & $\begin{array}{c}\text { Constant in the Dubinin-Astakhov } \\
\text { Equation }\end{array}$ & Subscripts & \\
\hline $\mathrm{Gn}$ & Solar radiation $\left(\mathrm{W} / \mathrm{m}^{2}\right)$ & a & adsorption \\
\hline $\mathrm{m}$ & mass $(\mathrm{kg})$ & ads & adsorbent \\
\hline $\mathrm{n}$ & $\begin{array}{c}\text { Constant in the Dubinin-Astakhov } \\
\text { Equation }\end{array}$ & d & desorption \\
\hline $\mathrm{P}$ & Pressure $(\mathrm{Pa})$ & $c d$ & condenser \\
\hline $\mathrm{P}_{\mathrm{s}}$ & Saturation Pressure $(\mathrm{Pa})$ & ev & evaporater \\
\hline $\mathrm{Q}_{\mathrm{f}}$ & Cold production $(J)$ & $\mathrm{v}$ & glass \\
\hline $\mathrm{q}$ & $\begin{array}{l}\text { Water concentration inside the } \\
\text { zéolithe }(\mathrm{kg} / \mathrm{kg})\end{array}$ & ext & outside \\
\hline S & Area $\left(m^{2}\right)$ & $\mathrm{amb}$ & ambient \\
\hline $\mathrm{T}$ & Température (K) & zeo & zeolithe \\
\hline $\mathrm{t}$ & Time (s) & $\min / \max$ & minimum \\
\hline $\mathrm{W}_{\mathrm{o}}$ & $\begin{array}{c}\text { Parameter of Dubinin-Astrakhov } \\
\text { Equation }\left(\mathrm{m}^{3} / \mathrm{kg}\right)\end{array}$ & $\max$ & maximum \\
\hline $\mathrm{L}(\mathrm{T})$ & Latent heat of vaporization $(\mathrm{J} / \mathrm{kg})$ & g & generation \\
\hline & Greek Letters: & $\mathrm{cv}$ & convection \\
\hline$\alpha$ & absorptance & moy & average \\
\hline$\tau$ & Transmitance & eau & water \\
\hline$\Delta t$ & Time step (s) & & \\
\hline
\end{tabular}

Submit or recommend next manuscript to SCIRP and we will provide best service for you:

Accepting pre-submission inquiries through Email, Facebook, LinkedIn, Twitter, etc. A wide selection of journals (inclusive of 9 subjects, more than 200 journals) Providing 24-hour high-quality service User-friendly online submission system Fair and swift peer-review system Efficient typesetting and proofreading procedure Display of the result of downloads and visits, as well as the number of cited articles Maximum dissemination of your research work

Submit your manuscript at: http://papersubmission.scirp.org/

Or contact epe@scirp.org 